\title{
ORIGINAL
}

\section{Performance of a guideline-recommended algorithm for prognostication of poor neurological outcome after cardiac arrest}

\author{
Marion Moseby-Knappe ${ }^{1^{*}}$ (D) Erik WesthalI², Sofia Backman², Niklas Mattsson-Carlgren 1,3,4, Irina Dragancea', \\ Anna Lybeck ${ }^{5}$, Hans Friberg ${ }^{6}$, Pascal Stammet ${ }^{7}$, Gisela Lilja' ${ }^{1}$ Janneke Horn ${ }^{8}$, Jesper Kjaergaard ${ }^{9}$, \\ Christian Rylander ${ }^{10}$, Christian Hassager ${ }^{9}$, Susann Ullén ${ }^{11}$, Niklas Nielsen ${ }^{12}$ and Tobias Cronberg ${ }^{1}$
}

(c) 2020 The Author(s)

\begin{abstract}
Purpose: To assess the performance of a 4-step algorithm for neurological prognostication after cardiac arrest recommended by the European Resuscitation Council (ERC) and the European Society of Intensive Care Medicine (ESICM).

Methods: Retrospective descriptive analysis with data from the Target Temperature Management (TTM) Trial. Associations between predicted and actual neurological outcome were investigated for each step of the algorithm with results from clinical neurological examinations, neuroradiology (CT or MRI), neurophysiology (EEG and SSEP) and serum neuron-specific enolase. Patients examined with Glasgow Coma Scale Motor Score (GCS-M) on day 4 (72-96 h) post-arrest and available 6-month outcome were included. Poor outcome was defined as Cerebral Performance Category 3-5. Variations of the ERC/ESICM algorithm were explored within the same cohort.

Results: The ERC/ESICM algorithm identified poor outcome patients with $38.7 \%$ sensitivity $(95 \% \mathrm{CI} 33.1-44.7)$ and $100 \%$ specificity ( $95 \%$ Cl 98.8-100) in a cohort of 585 patients. An alternative cut-off for serum neuron-specific enolase, an alternative EEG-classification and variations of the GCS-M had minor effects on the sensitivity without causing false positive predictions. The highest overall sensitivity, 42.5\% (95\% Cl 36.7-48.5), was achieved when prognosticating patients irrespective of GCS-M score, with 100\% specificity (95\% Cl 98.8-100) remaining.

Conclusion: The ERC/ESICM algorithm and all exploratory multimodal variations thereof investigated in this study predicted poor outcome without false positive predictions and with sensitivities $34.6-42.5 \%$. Our results should be validated prospectively, preferably in patients where withdrawal of life-sustaining therapy is uncommon to exclude any confounding from self-fulfilling prophecies.
\end{abstract}

Keywords: Cardiac arrest, Prognostication, Guideline algorithm, Prognostic accuracy, Coma

*Correspondence: marion.moseby knappe@med.lu.se

${ }^{1}$ Department of Clinical Sciences Lund, Neurology, Skåne University

Hospital, Lund University, Getingevägen 4, 22241 Lund, Sweden

Full author information is available at the end of the article 


\section{Introduction}

The European Resuscitation Council (ERC) and the European Society of Intensive Care Medicine (ESICM) published joint guidelines for neurological prognostication after cardiac arrest (CA) in 2014 and 2015 [1, 2]. The included algorithm consists of 4 separate steps and was based on the current level of evidence for individual methods and expert opinions about combinations of methods.

According to ERC/ESICM, prediction of neurological recovery cannot be done with high confidence before $72 \mathrm{~h}$ after CA and only after confounding factors such as metabolic derangements or effects of residual sedation and muscle-relaxants are excluded (Step 0) [1]. In Step 1, the patient's best response to painful stimuli is evaluated according to the Glasgow Coma Scale Motor Score (GCS-M) as a screening criterion. If patients either have no motor response to pain or extend the extremities $(\mathrm{GCS}-\mathrm{M} \leq 2)$, they will be assessed further whilst patients with at least stereotypic flexor response (GCS-M 3 ) or better are excluded from further prognostication. In Step 2 the most robust predictors are considered. Outcome is "very likely poor" if a patient has bilaterally absent corneal and pupillary light reflexes, and/or bilaterally absent N20 response on short-latency somatosensory evoked potentials (SSEP). A patient not fulfilling the Step-2-criteria should be re-examined after $\geq 24 \mathrm{~h}$. If GCS-M is still $\leq 2$, Step 3 of the algorithm states that outcome will be "likely poor" if there are $\geq 2$ pathological findings of the following: "high" serum neuron-specific enolase (NSE) according to locally established cut-off values, unreactive burst-suppression or unreactive status epilepticus on electroencephalography (EEG), generalized oedema on head computed tomography $(\mathrm{CT}) \leq 24 \mathrm{~h}$ post-arrest or on magnetic resonance imaging (MRI) or early ( $\leq 48 \mathrm{~h}$ ) status myoclonus. Since the publication of the ERC/ESICM guidelines, a standardized classification of post-arrest EEG patterns has been suggested [3-6] and two large studies on serum NSE levels have been published $[7,8]$.

The aim of this study was to assess the performance of the ERC/ESICM algorithm in a large international cohort of patients comparing predicted neurological outcome with the outcome reported 6 months post-arrest. Additionally, we wanted to identify strengths and weaknesses of the current algorithm, and explore possible modifications.

\section{Methods}

Retrospective descriptive analysis using data from the international multicentre Target Temperature after Out-of-hospital Cardiac Arrest (TTM) Trial

\section{Take-home message}

In this cohort, the 2015 ERC/ESICM algorithm reliably predicted poor outcome after out-of-hospital cardiac arrest, but many patients with a poor outcome were not detected. Explorative versions to simplify the algorithm also correctly predicted poor outcome in this study, but our results should be validated, preferably in patients where withdrawal of life-sustaining therapy is uncommon.

randomizing 939 adult patients with CA of presumed cardiac cause to a targeted temperature management of $33^{\circ} \mathrm{C}$ or $36^{\circ} \mathrm{C}$ between 2010 and 2013. Rationale, design and results have previously been published $[9,10]$. Ethical consent was obtained in each participating country [10]. The TTM-database contains information on clinical data, patient demographics, neurological prognostication, withdrawal of life-sustaining-therapy (WLST) and follow-up at 6 months after CA [11, 12]. Poor neurological outcome was defined as Cerebral Performance Category Scale (CPC) 3-5 (severe cerebral disability, vegetative state or brain death) [13]. GCS-M and clinical seizures were evaluated daily; brain stem reflexes were registered at formal neurological prognostication $\geq 108 \mathrm{~h}$ post-arrest $[10,11,14]$. In this study, we used GCS-M on day 4 (72-96 h post-arrest), since this is closest to guideline recommendations $[1,2]$.

A routine EEG was performed in unconscious patients $48-72 \mathrm{~h}$ post-arrest, and if available, SSEP was performed during normothermia and was recommended for patients unconscious between 84 and $108 \mathrm{~h}$ after cardiac arrest [12]. Blinded retrospective evaluation of original EEG data was based on the terminology of the American Clinical Neurophysiology Society [15] and classified into unreactive burst-suppression and unreactive status epilepticus (abundant rhythmic/ periodic discharges) according to ERC/ESICM [2]. In an exploratory analysis the recently proposed standardized highly malignant EEG patterns was applied [3, 4, $15,16]$.

Serum samples were collected at 24,48 and $72 \mathrm{~h}$ after CA, stored in a central biobank and analysed after TTMtrial completion [7]. We defined NSE levels as "high" if $\geq 48 \mathrm{pg} / \mathrm{mL}$ at $48 \mathrm{~h}$ and $/$ or $\geq 38 \mathrm{pg} / \mathrm{mL}$ at $72 \mathrm{~h}$, corresponding to $2 \%$ false positive rates for poor outcome as previously published [7]. In a sensitivity analysis, we explored an alternative cut-off $\geq 33 \mathrm{pg} / \mathrm{mL}$ at 48 and/ or $72 \mathrm{~h}$ as suggested in previous guidelines $[17,18]$ and recently used validating the ERC/ESICM algorithm [19, 20]. Both CT and MRI were performed on clinical indication and evaluated for generalized oedema by local radiologists in a pragmatic approach similar to clinical practice. The first available CT was included in this study [21]. 
According to trial protocol, WLST was permitted when any of the following criteria were fulfilled; (1) status myoclonus $\leq 24 \mathrm{~h}$ post-arrest and bilaterally absent N20 potentials after rewarming, (2) persisting coma $(\mathrm{GCS}-\mathrm{M} \leq 2)$ AND bilaterally absent N20 potentials OR a treatment refractory status epilepticus at $\geq 108 \mathrm{~h}$ postarrest, (3) brain death according to national legislation or (4) ethical reasons (also including treatment refractory shock or end-stage multiorgan failure) [12]. If applicable, the presumed cause of death was reported by the physician responsible for patient care [12].

\section{Statistical analyses}

Continuous variables are expressed as median (interquartile range) and categorical variables in numbers (percentages). Analyses were performed using two different cohorts. Prognostic accuracies of the ERC/ESICM algorithm and explorative variations thereof were calculated in patients examined with GCS-M on day $4(n=585)$. Missing diagnostic examinations were regarded "negative/non-pathological", allowing evaluation according to remaining ERC/ESICM criteria similar to clinical practice.

To reduce selection bias, prognostic accuracies of single and combinations of diagnostic methods were calculated using all patients with 6-month outcome registered $(n=933)$. Only patients actually examined were included when calculating prognostic accuracies. Prognostic accuracies of methods were compared to each other using the McNemar's Test.

The term "true" was used when predicted outcome and reported outcome were identical, whilst "false" indicated that outcome prediction was contrary to the reported outcome. "Negative" referred to good outcome (CPC12 ), and "positive" referred to poor outcome (CPC3-5). For example, "true positive" (TP) indicated a patient where both predicted and reported outcome was poor. 95\% confidence intervals were calculated with Wilson's method. Analyses were performed using R version 3.5.1 (The R Foundation for Statistical Computing) [22].

\section{Results}

\section{Prognostic performance of the ERC/ESICM algorithm}

Of 939 patients, 180 were sedated (Step 0), 140 died before day 4 and 34 had missing data (eFig. 1, Table 1). Of the included patients, 205/585 (35\%) had GCS-M $\leq 2$ (Table 2).

\section{Prediction of poor outcome}

Figure 1 shows predicted and reported outcome in each step of the algorithm. In the first step, 380 patients had GCS-M $\geq 3$ of which 305 patients with good outcome (true negative, TN) and 75 with poor outcome (false negative, FN). Patients with GCS-M $\leq 2$ were examined further. In Step 2, all 67 patients fulfilling either one or both criteria for "poor outcome very likely" had poor outcome (TP). Of 138 patients evaluated in Step 3, 36 additional patients were correctly identified as TP by fulfilling criteria for $\geq 2$ pathological findings. Among the remaining 102 patients, 14 had good outcome (TN) and 88 had poor outcome (FN). The majority of FN patients had died at 6 months: 137/163 (84\%). Presumed cause of death was neurological in 79/137 (57.7\%). WLST due to neurological futility was performed in $59.2-87.7 \%$ of poor outcome patients with pathological prognostic findings (eTable 2). Of patients with bilaterally absent SSEP N20, 46/53 (86.8\%) had $\geq 1$ additional pathological Step 2 or 3 finding (eFig. 2).

In this cohort, the ERC/ESICM algorithm predicted poor outcome (CPC 3-5) with $100 \%$ specificity (95\% CI 98.8-100) and 38.7\% sensitivity (95\% CI 33.1-44.7). Applying an alternative definition of poor outcome (CPC $4-5)$, the overall sensitivity was $41.8 \%$ (95\% CI 35.8-48.1) and specificity was $99.7 \%$ (95\% CI 98.4-100) due to $1 \mathrm{FP}$ patient with CPC 3 (eFig. 3).

\section{Prediction of good outcome}

Three hundred and nineteen (54.5\%) patients had good outcome. GCS-M $\geq 3$ on day 4 predicted good outcome with $95.6 \%$ sensitivity (95\% CI 92.8-97.4) and 71.8\% specificity (95\% CI 66.1-76.9). Good outcome patients with GCS-M $\geq 3$ were significantly younger and had shorter time to return of spontaneous circulation and more often an initial shockable rhythm on ECG compared to GCS-M $\geq 3$ patients with a poor outcome (eTable 3). All 14 patients with GCS-M $\leq 2$ on day 4 and good outcome were male, most had ventricular fibrillation as the initial rhythm on ECG, and their NSE levels were below the cut-off for poor outcome applied in this study in all but one patient (eTable 4). Overall, the ERC/ESICM algorithm predicted good outcome for patients who did not fulfil the criteria for a "very likely" or "likely" poor outcome (TN) with $100 \%$ sensitivity (95\% CI $98.8-100)$ and $38.7 \%$ specificity ( $95 \%$ CI $33.1-44.7$, Fig. 1 ). The majority of good outcome patients 310/319 (97.2\%) had no pathological findings in the examinations performed within this study. Nine had single pathological findings: one had early status myoclonus, one fulfilled ERC/ESICM criteria for unreactive status epilepticus on EEG $75 \mathrm{~h}$ after CA, and the remaining 7 patients had elevated NSE levels at $48 \mathrm{~h}$ and/or $72 \mathrm{~h}$, of which 3 had decreasing levels of NSE from 24 to $72 \mathrm{~h}$ (eTable 5). Most patients (6/9) with single FP findings were awake and obeying commands (GCS-M 6) on day 4. Details on GCS-M levels and numbers of pathological findings are displayed in eTables $6 \mathrm{~A}+\mathrm{B}$. 
Table 1 Characteristics of the two cohorts of patients used for statistical analyses

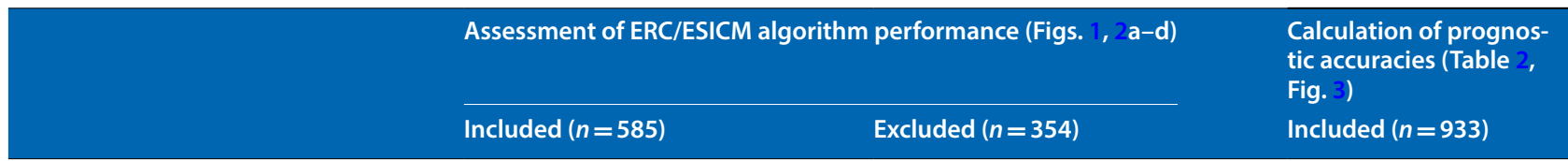

\section{Baseline data}

\begin{tabular}{|c|c|c|c|}
\hline Age (years) & $64(56-72)$ & $66(57-73)$ & $65(57-73)$ \\
\hline Male & 479 (81.9) & $282(79.7)$ & $756(81)$ \\
\hline Minutes to ROSC & $24(15-37)$ & $27(20-41)$ & $25(17-39)$ \\
\hline Initial rhythm shockable & $473(80.8)$ & $256(72.3)$ & $725(77.8)$ \\
\hline CA place of residence & $301(51.5)$ & $199(56.4)$ & $498(53.4)$ \\
\hline $\operatorname{TTM} 33^{\circ} \mathrm{C}$ & $279(47.7)$ & $194(54.8)$ & $469(48.1)$ \\
\hline \multicolumn{4}{|l|}{ Examinations available } \\
\hline GCS-M day 4 & $585 / 585(100)$ & $3 / 354(0.8)$ & $585 / 933(62.7)$ \\
\hline Pupillary light reflexes & $213 / 585(36.4)$ & $96 / 354(27.1)$ & $309 / 933(33.1)$ \\
\hline Corneal reflexes & 208/585 (35.6) & $93 / 354(26.3)$ & $302 / 933(32.4)$ \\
\hline S. myoclonus $\leq 48 \mathrm{~h}$ & $585 / 585(100)$ & $354 / 354(100)$ & 933/933 (100) \\
\hline NSE $48 \mathrm{~h}$ & $431 / 585(73.7)$ & $186 / 354(52.5)$ & $614 / 933(65.8)$ \\
\hline NSE $72 \mathrm{~h}$ & $411 / 585(70.3)$ & $163 / 354(46)$ & $572 / 933(61.3)$ \\
\hline SSEP & 144/585 (26.6) & $57 / 354(16.1)$ & 200/933 (21.4) \\
\hline Time to SSEP (h) & $89(69-115)$ & $102(75-120)$ & $93(69-117)$ \\
\hline EEG & 210/585 (35.9) & $96 / 354(27.1)$ & $305 / 933(32.7)$ \\
\hline Time to EEG (h) & $72(51-95)$ & $76(51-115)$ & $72(51-103)$ \\
\hline CT & 219/585 (37.4) & 138/354 (39) & $356 / 933(38.2)$ \\
\hline Time to CT (h) & $10(2-81)$ & $5(2-65)$ & $14(2-87)$ \\
\hline MRI & 20/585 (3.4) & 15/354 (4.2) & 35/933 (3.8) \\
\hline Time to MRI (h) & $214(147-320)$ & $205(140-310)$ & $214(143-312)$ \\
\hline \multicolumn{4}{|l|}{ Outcome } \\
\hline CPC 1 & $272(46.5)$ & $106(29.9)$ & $378(40.5)$ \\
\hline CPC 2 & $47(8)$ & $15(4.2)$ & $62(6.6)$ \\
\hline CPC 3 & $22(3.8)$ & $15(4.2)$ & $37(4)$ \\
\hline CPC 4 & $4(0.7)$ & $3(0.8)$ & $7(0.8)$ \\
\hline CPC 5 & $240(41)$ & $209(59)$ & $449(48.1)$ \\
\hline \multicolumn{4}{|l|}{ WLST } \\
\hline WLST/CPC 5 & $168 / 240(70)$ & $148 / 209(70.8)$ & $316 / 449(70.4)$ \\
\hline Neurological & 128/168 (76.2) & $83 / 148(56.1)$ & $211 / 316(66.8)$ \\
\hline Multiorgan failure & $17 / 168(10.1)$ & $37 / 148(25)$ & $54 / 316(17.1)$ \\
\hline Failing circulation & 20/168 (11.9) & $57 / 148(35.8)$ & $77 / 316(24.4)$ \\
\hline Ethical & $28 / 168(16.7)$ & $18 / 148(12.2)$ & $46 / 316(14.6)$ \\
\hline Medical comorbidities & 6/168 (3.6) & 16/148 (10.8) & $22 / 316(7)$ \\
\hline Days from CA to WLST & $6(5-7)$ & $3(2-6)$ & $5(3-7)$ \\
\hline
\end{tabular}

Characteristics of cohorts included and excluded in the statistical analyses (flow chart of inclusion available in eFig. 1). When assessing the overall prognostic performance of the ERC/ESICM algorithm, all patients with day 4 Glasgow Coma Scale Motor Score (GCS-M) were included $(n=585)$. For calculations of single and combined prognostic accuracies, all patients with 6-month outcome were included $(n=933)$. Continuous variables are displayed as median and interquartile range. Categorical variables are shown in numbers and percentages. CA, cardiac arrest; ROSC, return of spontaneous circulation; TTM, targeted temperature management; NSE, serum neuron-specific enolase; SSEP, short-latency somatosensory evoked potentials; S. myoclonus, generalized status myoclonus; EEG, electroencephalogram; $\mathrm{CT}$, head computed tomography; MRI, head magnetic resonance imaging; CPC, Cerebral Performance Category Scale at 6-month follow-up; WLST/CPC 5, withdrawal of life-sustaining therapy in patients who were dead 6 months after cardiac arrest;h, hours after cardiac arrest

\section{Exploratory variations of the current ERC/ESICM algorithm Alternative cut-off values for NSE}

Three additional poor outcome patients were identified by the algorithm, when using NSE cut-off $\geq 33 \mathrm{pg} / \mathrm{mL}$ at 
Table 2 Sensitivities and specificities of single prognostic methods as recommended by ERC/ESICM and variations thereof

\begin{tabular}{|c|c|c|c|c|c|c|c|c|}
\hline Method & Sensitivity (95\% CI) & Specificity (95\% CI) & $\mathrm{TP}$ & TN & FP & FN & $N=$ & Poor outcome \\
\hline GCS-M $\leq 2$ & $71.8(66.1-76.9)$ & $95.6(92.8-97.4)$ & 191 & 305 & 14 & 75 & 585 & $266(45.5)$ \\
\hline GCS-M $\leq 3$ & $77.1(71.7-81.7)$ & $92.8(89.4-95.2)$ & 205 & 296 & 23 & 61 & 585 & $266(45.5)$ \\
\hline GCS-M $\leq 4$ & $85.7(81-89.4)$ & $83.7(79.3-87.4)$ & 228 & 267 & 52 & 38 & 585 & $266(45.5)$ \\
\hline $\mathrm{PR} / \mathrm{CR}$ & $20.1(15.6-25.4)$ & $100(92.4-100)$ & 51 & 47 & 0 & 203 & 301 & $254(84.4)$ \\
\hline SSEP & $45.3(37.9-53.1)$ & $97.4(86.8-99.6)$ & 73 & 38 & 1 & 88 & 200 & $161(80.5)$ \\
\hline $\mathrm{NSE} \geq 33^{*} / * *$ & $67.3(61.9-72.3)$ & $89.9(86.2-92.7)$ & 208 & 303 & 34 & 101 & 646 & $309(47.8)$ \\
\hline $\mathrm{NSE} \geq 48^{*} / \geq 38^{* *}$ & $60.2(54.6-65.5)$ & $96.4(94-98)$ & 186 & 325 & 12 & 123 & 646 & $309(47.8)$ \\
\hline EEG ERC/ESICM & $31.7(25.9-38.1)$ & $98.8(93.6-99.8)$ & 70 & 83 & 1 & 151 & 305 & $221(72.5)$ \\
\hline EEG "highly malignant" & $38(31.9-44.6)$ & 98.8 (93.6-99.8) & 84 & 83 & 1 & 137 & 305 & $221(72.5)$ \\
\hline S. Myoclonus $\leq 48 \mathrm{~h}$ & $6.9(5-9.5)$ & $99.8(98.7-100)$ & 34 & 439 & 1 & 459 & 933 & $493(53.8)$ \\
\hline $\mathrm{CT}$ & $32.3(26.7-38.4)$ & $98.3(94.2-99.6)$ & 76 & 119 & 2 & 159 & 356 & $235(66)$ \\
\hline MRI & $13(4.5-32.1)$ & $100(75.8-100)$ & 3 & 12 & 0 & 20 & 35 & $23(65.7)$ \\
\hline
\end{tabular}

Prognostic accuracies of methods using all available results in the entire TTM-cohort with 6-month outcome ( $n=933)$. The cohort is described in the right column in Table 1 and in eFig. 1. Results presented in numbers or in percentages with $95 \%$ confidence intervals. Only patients with available results were included in the statistical analyses. Poor neurological outcome was defined as Cerebral Performance Category Scale 3-5 at 6 months. GCS-M, Glasgow Coma Scale Motor Score on day 4 after cardiac arrest; PR/CR, bilaterally absent pupillary light reflexes and bilaterally absent corneal reflexes; SSEP; bilaterally absent N20 potentials on short-latency somatosensory evoked potentials; NSE, serum neuron-specific enolase in pg/mL * at $48 \mathrm{~h}$ and/or ** at $72 \mathrm{~h}$ post-arrest; EEG ERC/ESICM, unreactive burst-suppression or unreactive status epilepticus (abundant rhythmic/periodic discharges); EEG "highly malignant", suppressed background with or without periodic discharges or burst-suppression with or without discharges; $\mathrm{S}$. Myoclonus, presence of early status myoclonus $>30$ min $\leq 48 \mathrm{~h}$ after cardiac arrest; CT, visually evaluated generalized oedema seen as a reduced differentiation between grey and white matter by local radiologists; MRI, presence of generalized oedema on magnetic resonance imaging. TP, true positive (predicted and reported poor outcome); TN, true negative (predicted and reported good outcome); FP, false positive (predicted poor outcome, reported good outcome); FN, false negative (predicted good outcome, reported poor outcome)

either 48 and/or $72 \mathrm{~h}$ post-arrest, increasing the overall sensitivity of the algorithm slightly to $39.5 \%$ (95\% CI 33.8-45.5) without FP predictions.

\section{Highly malignant patterns on EEG}

By evaluating EEGs according to criteria for "highly malignant" patterns [3], three additional poor outcome patients were identified, increasing overall sensitivity to $39.8 \%$ (95\% CI 34.2-45.8) with preserved 100\% specificity (95\% CI 98.8-100). 44/210 (21\%) patients fulfilled ERC/ ESICM criteria for pathological EEG, 62/210 (29.5\%) the criteria for "highly malignant" EEG pattern, and 18/210 (8.6\%) fulfilled both criteria.

\section{GCS-M}

Twenty-three patients had GCS-M=3 on day 4,9 with good outcome and 14 with poor outcome. Using GCS-M $\leq 3$ as screening criteria, 6 additional poor outcome patients were correctly identified (Fig. 2a), increasing the overall sensitivity of the algorithm to $41 \%$ (95\% CI $35.2-47$ ) with remaining $100 \%$ specificity.

When prognosticating all patients according to Step 2 and 3 criteria irrespective of the GCS-M score, sensitivity increased further to $42.5 \%$ (95\% CI 36.7-48.5) without FP predictions (Fig. 2b). All TP patients had GCS-M $\leq 4$.

\section{Combing Steps 2 and 3}

We explored combining Steps 2 and 3 where any $\geq 2$ pathological findings were considered indicative of "poor outcome likely", either with GCS-M as a screening criterion (Fig. 2c) or without (Fig. 2d). The overall sensitivity of the algorithm decreased to $34.6 \%$ (95\% CI 29.1-40.5), but increased slightly again to $38.3 \%$ (95\% CI $32.7-44.3$ ) when GCS-M in Step 1 was removed. This decrease in sensitivity was due to 11 patients who had bilaterally absent SSEP N20-potentials $(n=7)$ or bilaterally absent pupillary and corneal reflexes $(n=4)$, but no other pathological findings. 8/11 (72.7\%) had WLST due to neurological futility (WLST-N). All TP patients according to these criteria had GCS-M $\leq 4$ (e'Table 6B).

\section{Single and combined prognostic accuracies}

Data from 933 patients were used when analysing the accuracies of methods for prognostication included in the ERC/ESICM algorithm (eFig. 1).

Among individual methods, early status myoclonus had the lowest sensitivity $(6.8 \%)$ to identify poor outcome patients, whilst NSE and GCS-M $\leq 2$ had the highest sensitivities for predicting poor outcome (60.2-67.3\% for NSE cut-off and $71.8 \%$ for GCS-M $\leq 2$, respectively) (Table 2). All pairs of methods predicted poor outcome with $100 \%$ specificity, with the exception of GCS-M $\leq 2$ in combination with elevated NSE, both methods with limited individual specificity (Fig. 3). When patients 
ERC/ESICM 2015 algorithm for prognostication of neurological outcome

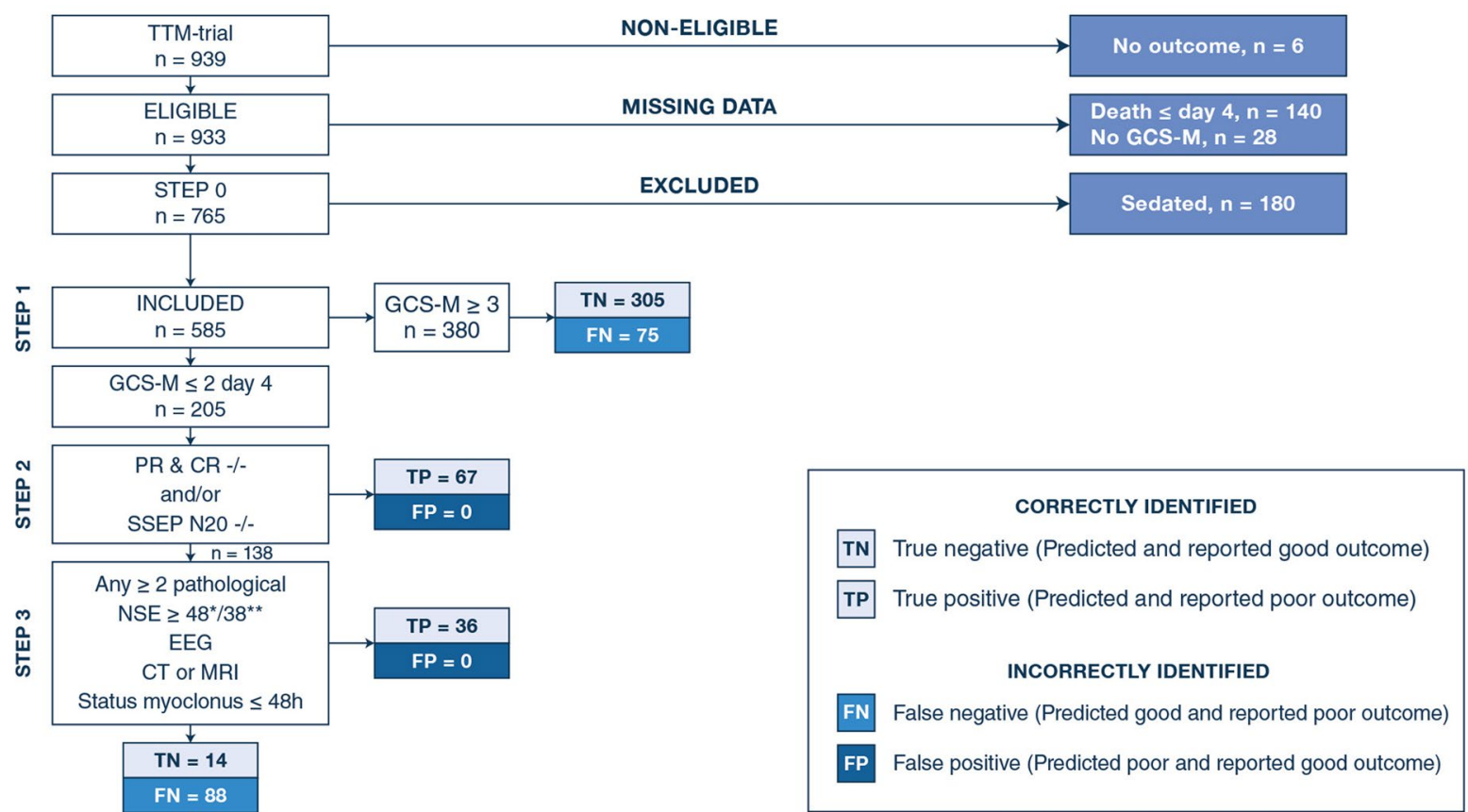

Fig. 1 This flow chart demonstrates the number of patients with 6-month outcome $(n=933)$, and patients excluded or included $(n=585)$ when assessing overall prognostic performance of the ERC/ESICM algorithm. In patients with day 4 Glasgow Coma Scale Motor Score (GCS-M), we present numbers of predicted and reported outcome when applying the current ERC/ESICM algorithm. PR \& CR -/- bilaterally absent pupillary light reflexes and bilaterally absent corneal reflexes; SSEP N20 -/- bilaterally absent N20 response on short-latency somatosensory evoked potentials; NSE, elevated serum neuron-specific enolase $\geq 48 \mathrm{pg} / \mathrm{mL}$ at $48 \mathrm{~h}$ and/or $\geq 38 \mathrm{pg} / \mathrm{mL}$ at $72 \mathrm{~h}$ after cardiac arrest; EEG, unreactive status epilepticus (abundant rhythmic/periodic discharges) or unreactive burst-suppression on EEG according to ERC/ESICM criteria [2; CT or MRI, generalized oedema on head computed tomography OR on magnetic resonance imaging; S. myoclonus, generalized status myoclonus $\leq 48 \mathrm{~h}$ after cardiac arrest; true positive, TP; predicted and reported outcome poor (CPC3-5); true negative, TN; predicted and reported outcome good (CPC1-2); false negative, FN; predicted good and reported poor. There were no false positive, FP, predictions of poor outcome in patients with reported good outcome

subjected to WLST-N were censored, sensitivities of individual methods decreased by $3-26.5 \%$, whilst specificities remained unchanged (eTable 7).

\section{Discussion}

Applied to the cohort of a large pragmatic international trial, the ERC/ESICM algorithm predicted poor neurological outcome without false positive predictions and correctly identified $38.7 \%$ of poor outcome patients. Despite various exploratory modifications with the same outcome definitions used, specificity remained at $100 \%$ in this cohort. No good outcome patient had $\geq 2$ pathological findings and only $3 \%$ had 1 pathological finding, elevated NSE being the most common.

The ERC/ESICM algorithm failed to identify $60 \%$ of the poor outcome patients, among whom the "presumed cause of death" was neurological in approximately $60 \%$. An algorithm intended for identifying cerebral injuries cannot be expected to identify the remaining patients with other causes of death. Maintaining a very high specificity is essential for an algorithm predicting poor outcome, but improved sensitivity is nevertheless desirable. Two single-centre studies recently validated the ERC/ESICM algorithm and both reassuringly also concluded on $100 \%$ specificity, but WLST was permitted due to specified criteria in both studies $[19,20]$. The reported sensitivities for the ERC/ESICM algorithm were 18-26\% and $32 \%$, respectively $[19,20]$.

The sensitivity of a prognostic method or an algorithm will vary depending on the extent to which the different prognostic methods are available and which definitions are used for pathological findings, as well as the selection of patients included. In our study, this is illustrated by the low sensitivity of the strictly defined status myoclonus (6.9\%) and the relatively high sensitivity of an elevated NSE (60.2-67.3\%), frequently analysed due to the common biobank.

The ERC/ESICM recommends GCS-M 1-2 as a screening criterion [1]. Our results confirm that GCS-M should not be used to make decisions on level-of-care 


\section{Exploratory variations of the 2015 ERC/ESICM algorithm}

A Step 1 Screening criterion including GCS-M $\leq 3$

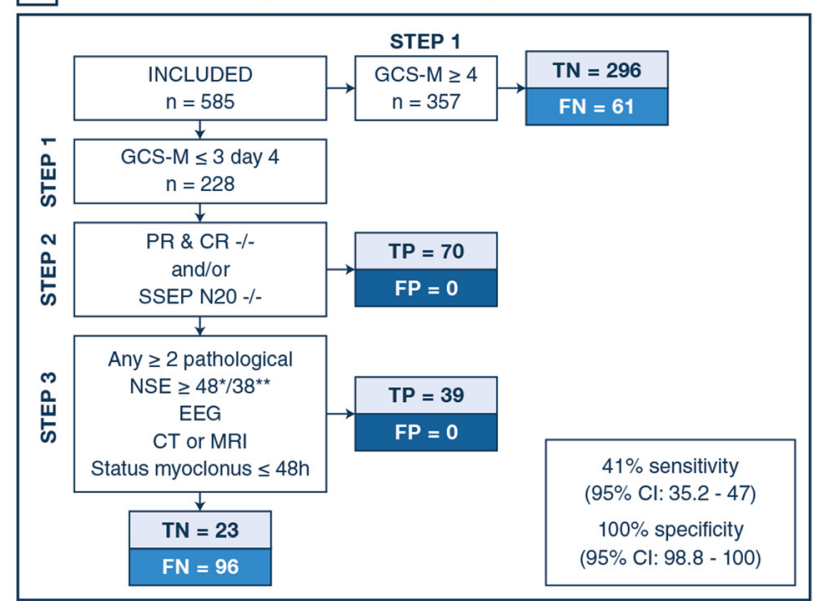

C Combining Steps 2 and 3

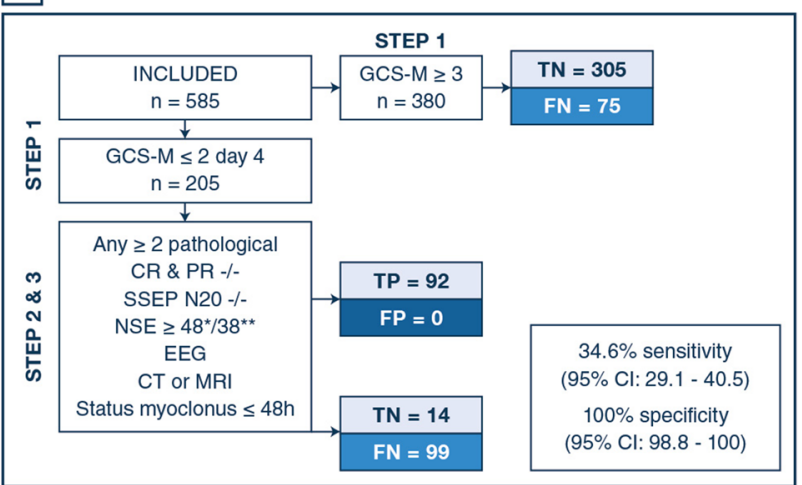

B Excluding Step 1 GCS-M

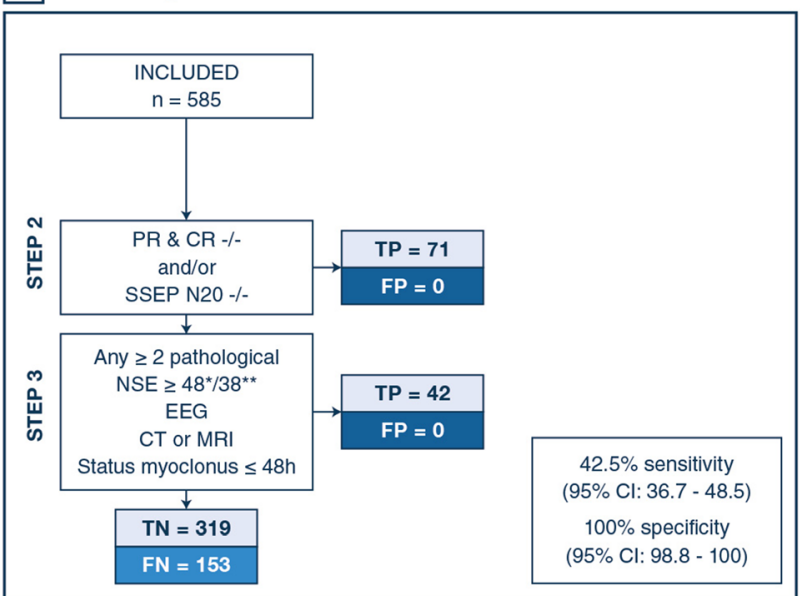

D Combining Steps 2 and 3 without GCS-M in Step 1

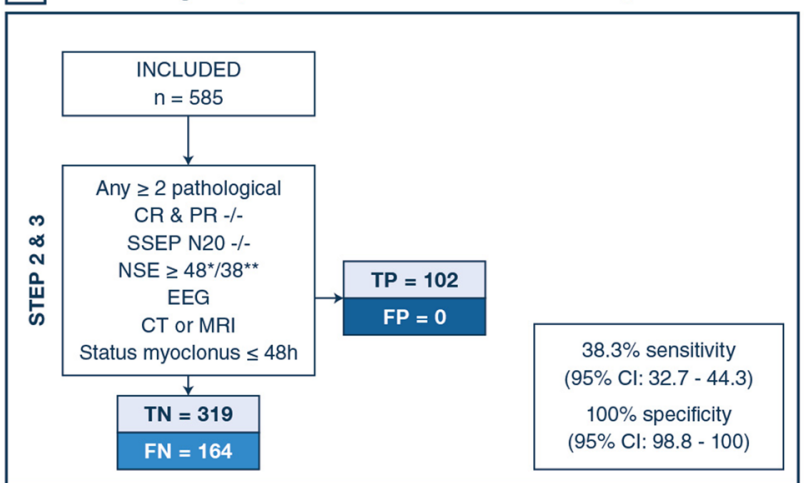

Fig. 2 Modified versions of Fig. 1 with exploratory alterations of the ERC/ESICM algorithm. Step 0 has been removed for clarity and is identical to Fig. 1. The figures $\mathbf{a}+\mathbf{b}$ demonstrate how alterations of GCS-M as a screening criterion in Step 1 impact prognostic accuracy of the algorithm. In $\mathbf{a}$, patients with day 4 GCS-M $\leq 3$ are prognosticated further, and in $\mathbf{b}$, patients are prognosticated irrespectable of GCS-M. In $\mathbf{c}$, any $\geq 2$ pathological findings in Steps 2 and 3 combined are considered indicative of poor outcome (as in the TTM2 and TAME Trials [39, 40], but we here used the ERC/ ESICM definitions of pathological EEG [41] as stated in the methods section). d Represents the simplest model of multimodal prognostication, with Steps 2 and 3 combined (as in c), but without considering GCS-M in Step 1. Pathological findings were defined according to ERC/ESICM criteria [2] as described in the legend of Fig. 1 and in the methods section. True positive, TP; predicted and reported outcome poor (CPC3-5), True negative, TN; predicted and reported outcome good (CPC1-2), False negative, FN; predicted good and reported poor outcome. There were no false positive, FP, predictions of poor outcome in patients with reported good outcome. 95\% confidence intervals (Cl) were calculated with Wilson's method

due to limited specificity. Evaluation of persisting coma by motor score may anyhow be adequate to differentiate between unconscious patients in need of further prognostication and those with a presumed good outcome. In this study, a considerable fraction of patients with GCS-M 3-4 had poor outcome and $\geq 2$ pathological prognostic findings, and it may be considered whether the current dichotomization should remain between GCS-M 2-3 in future guideline algorithms.

As supported by our results, false positive findings may occur with all methods currently used for prognostication, emphasizing the importance of a multimodal approach to reduce the risk of overly pessimistic predictions [8, 23-26]. Six patients with single pathological findings were awake and obeying commands on day 4 , illustrating that sufficient time for recovery post-arrest is also an important part of neurological prognostication $[1,27]$.

The ERC/ESICM algorithm permits unimodal prognostication using SSEP, whilst the TTM-trial protocol permitted unimodal prognostication for patients fulfilling specific SSEP or EEG criteria [1, 11]. Applying a stricter 
Sensitivities and specificities for prognostic methods included in Steps 1-3 in the ERC/ESICM algorithm

\begin{tabular}{|c|c|c|c|c|c|c|c|c|c|}
\hline \multirow{2}{*}{\multicolumn{2}{|c|}{ Variable }} & \multirow{3}{*}{$\begin{array}{c}\begin{array}{c}\text { Step } 1 \\
\text { GCS-M } \leq 2\end{array} \\
\begin{array}{c}71.8 / 95.6 \\
(585)\end{array}\end{array}$} & \multicolumn{2}{|c|}{ Step 2} & \multicolumn{5}{|c|}{ Step 3} \\
\hline & & & \multirow{2}{*}{$\begin{array}{c}\text { PR/CR } \\
\begin{array}{c}18.3 / 100 \\
(208)\end{array}\end{array}$} & \multirow{2}{*}{$\begin{array}{c}\text { SSEP } \\
\begin{array}{c}43.4 / 100 \\
(144)\end{array}\end{array}$} & \multirow{2}{*}{$\begin{array}{c}\text { NSE } \\
\begin{array}{c}55.7 / 99.6 \\
(455)\end{array}\end{array}$} & \multirow{2}{*}{$\begin{array}{c}\text { S. Myocl. } \\
\begin{array}{c}6.0 / 100 \\
(585)\end{array}\end{array}$} & \multirow{2}{*}{ 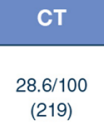 } & \multirow{2}{*}{$\begin{array}{c}\text { EEG } \\
24.7 / 100 \\
(210)\end{array}$} & \multirow{2}{*}{$\begin{array}{c}\text { MRI } \\
\begin{array}{c}9.1 / 100 \\
(20)\end{array}\end{array}$} \\
\hline 产 & GCS-M $\leq 2$ & & & & & & & & \\
\hline & $\mathrm{PR} / \mathrm{CR}$ & $\begin{array}{c}18.3 / 100 \\
(208)\end{array}$ & $\begin{array}{c}20.1 / 100 \\
(301)\end{array}$ & $\begin{array}{c}16.8^{* * * * / 100} \\
(164)\end{array}$ & $\begin{array}{c}16.5^{* \star * * / 100} \\
(224)\end{array}$ & $\begin{array}{c}2.0^{0+* * * / 100} \\
(301)\end{array}$ & $\begin{array}{c}10.0^{* *} / 100 \\
(165)\end{array}$ & $\begin{array}{c}4.7^{\star *} / 100 \\
(202)\end{array}$ & $\begin{array}{c}5.0 / 100 \\
(24)\end{array}$ \\
\hline & SSEP & $\begin{array}{c}43.4 / 100 \\
(144)\end{array}$ & $\begin{array}{c}16.8^{* * *} / 100 \\
(164)\end{array}$ & $\begin{array}{c}45.3 / 97.4 \\
(200)\end{array}$ & 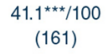 & $\begin{array}{c}8.7 / 100 \\
(200)\end{array}$ & $\begin{array}{c}15.4 / 100 \\
(98)\end{array}$ & $\begin{array}{c}10.4 / 100 \\
(163)\end{array}$ & $\begin{array}{l}5.3 / 100 \\
(22)\end{array}$ \\
\hline \multirow{5}{*}{ 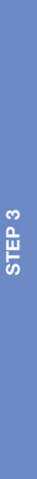 } & NSE & $\begin{array}{c}55.7 / 99.6 \\
(455)\end{array}$ & $\begin{array}{c}16.5^{+\star * *} / 100 \\
(224)\end{array}$ & $\begin{array}{c}\begin{array}{c}41.1^{* * *} \\
(161)\end{array}\end{array}$ & $\begin{array}{c}60.2 / 96.4 \\
(646)\end{array}$ & $\begin{array}{l}5.2^{2+*+1} / 100 \\
(646)\end{array}$ & $\begin{array}{c}28.8^{* \star *} / 100 \\
(254)\end{array}$ & $\begin{array}{c}23.3^{\star \star \star} / 100 \\
(241)\end{array}$ & $\begin{array}{c}16.7^{*} / 100 \\
(24)\end{array}$ \\
\hline & $\begin{array}{l}\text { Status } \\
\text { Myoclonus }\end{array}$ & $\begin{array}{l}6.0 / 100 \\
(585)\end{array}$ & $\begin{array}{c}2.0+0^{* * *} / 100 \\
(301)\end{array}$ & $\begin{array}{l}8.7 / 100 \\
(200)\end{array}$ & $\begin{array}{c}5.2^{\star \star \star} / 100 \\
(646)\end{array}$ & $\begin{array}{c}6.9 / 99.8 \\
(933)\end{array}$ & $\begin{array}{c}2.1^{\star \star \star *} / 100 \\
(356)\end{array}$ & $\begin{array}{l}3.2^{\star \star \star \star} / 100 \\
(305)\end{array}$ & $\begin{array}{l}-1- \\
(35)\end{array}$ \\
\hline & CT & $\begin{array}{c}28.6 / 100 \\
(219)\end{array}$ & $\begin{array}{c}10.0^{* * / 100} \\
(165)\end{array}$ & $\begin{array}{c}15.4 / 100 \\
(98)\end{array}$ & $\begin{array}{c}28.8^{\star * \star *} / 100 \\
(254)\end{array}$ & $\begin{array}{l}2.1^{1 * * * / 100} \\
(356)\end{array}$ & $\begin{array}{c}32.3 / 98.3 \\
(356)\end{array}$ & $\begin{array}{c}12.0 / 100 \\
(164)\end{array}$ & $\begin{array}{c}7.7 / 100 \\
(18)\end{array}$ \\
\hline & EEG & $\begin{array}{l}24.7 / 100 \\
(210)\end{array}$ & $\begin{array}{c}4.7^{\star *} / 100 \\
(202)\end{array}$ & $\begin{array}{c}10.4 / 100 \\
(163)\end{array}$ & $\begin{array}{c}23.3^{* * *} / 100 \\
(241)\end{array}$ & $\begin{array}{c}3.2^{* * * t / 100} \\
(305)\end{array}$ & $\begin{array}{c}12.0 / 100 \\
(164)\end{array}$ & $\begin{array}{c}31.7 / 98.8 \\
(305)\end{array}$ & $\begin{array}{l}-1- \\
(25)\end{array}$ \\
\hline & MRI & $\begin{array}{c}9.1 / 100 \\
(20)\end{array}$ & $\begin{array}{l}5.0 / 100 \\
(24)\end{array}$ & $\begin{array}{c}5.3 / 100 \\
(22)\end{array}$ & $\begin{array}{c}16.7^{*} / 100 \\
(24)\end{array}$ & $\begin{array}{l}-/ \\
(35)\end{array}$ & $\begin{array}{c}7.7 / 100 \\
(18)\end{array}$ & $\begin{array}{l}-/- \\
(25)\end{array}$ & $\begin{array}{l}13 / 100 \\
(35)\end{array}$ \\
\hline
\end{tabular}

Fig. 3 Sensitivities and specificities of single and combined methods for prediction of poor outcome (CPC $3-5$ at 6 months) in percentages, numbers of examined patients in (). The overall cohort is described in eFig. 1 and in the right column of Table $1(n=933)$. Only patients examined with a single method (bold font) or with both methods within a combination (regular font) were included therefore sensitivities of single methods may differ between combinations. Significance levels of single prognostic accuracies within combinations in Step 2/3 were calculated using the McNemars's Test (eTables 1A+B) and are indicated by asterisks; ${ }^{*} p<0.05,{ }^{* *} p<0.01$, ${ }^{* *} p<0.001$. The absence of an asterisk (*) in Step 2/3 methods indicates that single sensitivities or specificities within combinations did not differ significantly. For example, in the combined model PR/CR and SSEP, ${ }^{* * *}$ signifies $p<0.001$, therefore one method had significantly higher sensitivity than the other method when calculated in patients examined with both methods. GCS-M $\leq 2$, Glasgow Coma Scale Motor Score on day 4 after cardiac arrest; PR/CR, bilaterally absent pupillary light reflexes AND bilaterally absent corneal reflexes

multimodal approach, any $\geq 2$ pathological findings predicted poor outcome with maximal specificity in unconscious patients irrespective of GCS-M level (Fig. 2c, d). In this multimodal approach, overall sensitivity was slightly decreased and we speculate that sensitivity may have been higher with an increased use of diagnostic methods.

The evidence for the ERC/ESICM algorithm consists largely of studies where withdrawal of therapy was permitted, and hence influence from the self-fulfilling prophecy cannot be excluded [1, 28, 29]. Whilst WLST was common in the TTM-trial, the trial proto-col was designed to avoid premature decisions, applying conservative rules for prognostication [11]. The prespecified TTM-criteria permitting WLST (SSEP, status myoclonus and EEG) partly overlaps with the ERC/ ESICM recommendations published 2 years after trial completion $[2,11]$. Bilaterally absent N20-potentials in combination with early status myoclonus or in isolation were considered predictive of poor outcome in the TTMtrial. Whilst SSEP is considered a very robust method for prognostication after cardiac arrest, the self-fulfilling prophecy may have affected most previous studies [25, $28,29]$. One patient with absent N20-potentials in the TTM-trial awoke before scheduled prognostication [11] and the majority of our patients lacking N20 potentials had $\geq 1$ additional prognostic finding indicating severe brain injury. We still cannot exclude the self-fulfilling prophecy affecting our results but find it reassuring that bilaterally absent N20 predicted poor outcome with $100 \%$ specificity in two recent studies where WLST was not practiced [30, 31].

When we calculated prognostic accuracies of the ERC/ ESICM algorithm using an alternative definition of poor outcome (CPC 4-5), one patient who fulfilled the criteria for "poor outcome likely" and survived with severe cerebral disability (CPC 3) was reclassified. Definitions 
of poor outcome vary between studies, and survival with CPC 3 includes a wider range of severe cerebral disabilities, some of which may be considered acceptable outcome by patients or caregivers.

Strengths of this study include the large cohort, a conservative and protocolized approach to prognostication and the extensive clinical information available $[9,10]$. Results of EEG and NSE have been obtained after the study in a blinded fashion, and all results on clinical tests, SSEPs, CT-examinations and decisions on level-of-care have been presented in separate projects $[3,4,7,11,14$, $16,21]$.

There are several limitations to this retrospective study. Some of the co-authors who designed the TTM-trial also participated in the ERC/ESICM recommendations for prognostication after cardiac arrest, creating a risk for inherent bias. Clinical neurological examinations in the TTM-trial were performed according to local routines. We acknowledge that an increased focus on neurological examination techniques might have improved prognostic performance, since imprecise testing may be common [32]. Neuroimaging and SSEP was often performed on clinical indication in patients with presumed poor neurological prognosis likely leading to selection bias. We included the first reported CT-examination despite guidelines only recommending $\mathrm{CT} \leq 24 \mathrm{~h}$ postarrest. A stricter application of the 24-h time limit would presumably have reduced overall sensitivity of the algorithm. However, recent studies indicate improved performance of brain CT after $24 \mathrm{~h}$ [21, 33, 34]. NSE cut-off values were defined from the same TTM-study cohort [7]. Despite NSE being analysed after trial completion, its prognostic performance may still be indirectly affected by WLST based on other predictors. For statistical reasons, we excluded the 24-h delay between Steps 2 and 3 and only included each prognostic method once in our analyses, which is an approximation of clinical practice where patients are continuously re-examined. In the future, quantitative methods such as pupillometry $[35,36]$, standardized evaluation of neuroimaging and electrophysiology or novel serum biomarkers [37, 38] might prove themselves valuable additions to the current algorithm.

\section{Conclusion}

In this cohort the ERC/ESICM algorithm and exploratory variations thereof predicted poor outcome without false positive predictions. The ERC/ESICM algorithm identified $38.7 \%$ of poor outcome patients, and patients not identified often had a non-neurological presumed cause of death. Our results should be validated in patients where withdrawal of life-sustaining therapy is uncommon to reduce the risk of self-fulfilling prophecies.

\section{Electronic supplementary material}

The online version of this article (https://doi.org/10.1007/s00134-020-06080-9) contains supplementary material, which is available to authorized users.

\begin{abstract}
Author details
${ }^{1}$ Department of Clinical Sciences Lund, Neurology, Skåne University Hospital, Lund University, Getingevägen 4, 22241 Lund, Sweden. ${ }^{2}$ Department of Clinical Sciences Lund, Clinical Neurophysiology, Skane University Hospital, Lund University, Lund, Sweden. ${ }^{3}$ Clinical Memory Research Unit, Department of Clinical Sciences Malmö, Lund University, Lund, Sweden. ${ }^{4}$ Wallenberg Center for Molecular Medicine, Lund University, Lund, Sweden. ${ }^{5}$ Department of Clinical Sciences Lund, Anaesthesia and Intensive Care, Skane University Hospital, Lund University, Lund, Sweden. ${ }^{6}$ Department of Clinical Sciences Lund, Anaesthesia and Intensive Care, Skane University Hospital, Lund University, Malmö, Sweden. ${ }^{7}$ Medical and Health Department, National Fire and Rescue Corps, Luxembourg, Luxembourg. ${ }^{8}$ Department of Intensive Care, Amsterdam UMC, Location Academic Medical Center, Amsterdam, The Netherlands. ${ }^{9}$ Department of Cardiology, Rigshospitalet and Department of Clinical Medicine, University of Copenhagen, Copenhagen, Denmark.

${ }^{10}$ Department of Anaesthesiology and Intensive Care Medicine, Institute of Clinical Sciences, Sahlgrenska Academy, University of Gothenburg, Gothenburg, Sweden. ${ }^{11}$ Clinical Studies Sweden - Forum South, Skane University Hospital, Lund, Sweden. ${ }^{12}$ Department of Clinical Sciences Lund, Anaesthesia and Intensive Care, Helsingborg Hospital, Lund University, Lund, Sweden.
\end{abstract}

\section{Acknowledgements}

Open access funding provided by Lund University. Funding for the study was provided by the Swedish Research Council, Swedish Heart Lung Foundation, Arbetsmarknadens Försäkringsaktiebolag Insurance Foundation, the Skåne University Hospital Foundations, the Gyllenstierna-Krapperup Foundation, and governmental funding of clinical research within the Swedish National Health System, the County Council of Skåne; the Swedish Society of Medicine; the Koch Foundation; TrygFonden (Denmark); European Clinical Research Infrastructures Network; Thelma Zoega Foundation; Stig and Ragna Gorthon Foundation; Thure Carlsson Foundation; Hans-Gabriel and Alice Trolle-Wachtmeister Foundation for Medical Research; Lions Research fund Skåne; South Swedish Hospital Region Research Funds; the Swedish Brain Foundation; the Lundbeck Foundation; and the Torsten Söderberg foundation at the Royal Swedish Academy of Sciences.

\section{Author contributions}

Concept and design: MMK, TC, CR, NN, SU. Acquisition, analysis, or interpretation of data: All authors. Drafting the manuscript: MMK, TC. Critical revision of the manuscript for important intellectual content and approved the version to be published: All authors. Statistical analysis: MMK, TC, SU, NM. Obtained funding: MMK, TC, NN. Administrative, technical, or material support: The authors would like to thank the TTM-trial investigators and the sponsors for their support. Supervision: TC, NM, NN, SU. Agree to be accountable for all aspects of the work in ensuring that questions related to the accuracy or integrity of any part of the work are appropriately investigated and resolved: All authors.

\section{Funding}

The funding organizations had no role in the design and conduct of the study; collection, management, analysis, and interpretation of the data; preparation, review, or approval of the manuscript; and decision to submit the manuscript for publication.

\section{Compliance with ethical standards}

\section{Conflicts of interest}

MMK, EW, SB, NM, ID, AL, PS, GL, JH, JK, CR, CH, SU and NN report no conflicts of interests. TC and HF participated in the 2014 ERC/ESICM advisory statement on neuroprognostication after cardiac arrest. 


\section{Ethical statement}

This study has been approved by the appropriate ethics committees in each participating country and has therefore been performed in accordance with the ethical standards laid down in the 1964 Declaration of Helsinki and its later amendments.

\section{Open Access}

This article is licensed under a Creative Commons Attribution-NonCommercial 4.0 International License, which permits any non-commercial use, sharing, adaptation, distribution and reproduction in any medium or format, as long as you give appropriate credit to the original author(s) and the source, provide a link to the Creative Commons licence, and indicate if changes were made. The images or other third party material in this article are included in the article's Creative Commons licence, unless indicated otherwise in a credit line to the material. If material is not included in the article's Creative Commons licence and your intended use is not permitted by statutory regulation or exceeds the permitted use, you will need to obtain permission directly from the copyright holder.To view a copy of this licence, visit http://creativecommons.org/licen ses/by-nc/4.0/

\section{Publisher's Note}

Springer Nature remains neutral with regard to jurisdictional claims in published maps and institutional affiliations.

\section{Received: 5 February 2020 Accepted: 30 April 2020}

Published online: 3 June 2020

\section{References}

1. Sandroni C, Cariou A, Cavallaro F, Cronberg T, Friberg H, Hoedemaekers C, Horn J, Nolan JP, Rossetti AO, Soar J (2014) Prognostication in comatose survivors of cardiac arrest: an advisory statement from the European Resuscitation Council and the European Society of Intensive Care Medicine. Resuscitation 85(12):1779-1789. https://doi.org/10.1016/j.resuscitat ion.2014.08.011

2. Nolan JP, Cariou A (2015) Post-resuscitation care: ERC-ESICM guidelines 2015. Intensive Care Med 41(12):2204-2206. https://doi.org/10.1007/ s00134-015-4094-5

3. Westhall E, Rossetti AO, van Rootselaar AF, Wesenberg Kjaer T, Horn J, Ullen S, Friberg H, Nielsen N, Rosen I, Aneman A, Erlinge D, Gasche Y, Hassager C, Hovdenes J, Kjaergaard J, Kuiper M, Pellis T, Stammet P, Wanscher M, Wetterslev J, Wise MP, Cronberg T, Investigators TT-t (2016) Standardized EEG interpretation accurately predicts prognosis after cardiac arrest. Neurology 86(16):1482-1490. https://doi.org/10.1212/wnl.0000000000 002462

4. Backman S, Cronberg T, Friberg H, Ullén S, Horn J, Kjaergaard J, Hassager C, Wanscher M, Nielsen N, Westhall E (2018) Highly malignant routine EEG predicts poor prognosis after cardiac arrest in the Target Temperature Management trial. Resuscitation 131:24-28

5. Rossetti AO, Tovar Quiroga DF, Juan E, Novy J, White RD, Ben-Hamouda N, Britton JW, Oddo M, Rabinstein AA (2017) Electroencephalography predicts poor and good outcomes after cardiac arrest: a two-center study. Crit Care Med 45(7):e674-e682. https://doi.org/10.1097/ccm.0000000000 002337

6. Duez CHV, Johnsen B, Ebbesen MQ, Kvaloy MB, Grejs AM, Jeppesen AN, Soreide E, Nielsen JF, Kirkegaard H (2019) Post resuscitation prognostication by EEG in 24 vs $48 \mathrm{~h}$ of targeted temperature management. Resuscitation 135:145-152. https://doi.org/10.1016/j.resuscitation.2018.10.035

7. Stammet P, Collignon O, Hassager C, Wise MP, Hovdenes J, Aneman A, Horn J, Devaux Y, Erlinge D, Kjaergaard J, Gasche Y, Wanscher M, Cronberg T, Friberg H, Wetterslev J, Pellis T, Kuiper M, Gilson G, Nielsen N, Investigators TT-t (2015) Neuron-specific enolase as a predictor of death or poor neurological outcome after out-of-hospital cardiac arrest and targeted temperature management at $33^{\circ} \mathrm{C}$ and $36^{\circ} \mathrm{C}$. J Am Coll Cardiol 65(19):2104-2114. https://doi.org/10.1016/j.jacc.2015.03.538

8. Streitberger KJ, Leithner C, Wattenberg M, Tonner PH, Hasslacher J, Joannidis M, Pellis T, Di Luca E, Fodisch M, Krannich A, Ploner CJ, Storm C (2017) Neuron-specific enolase predicts poor outcome after cardiac arrest and targeted temperature management: a multicenter study on
1,053 patients. Crit Care Med 45(7):1145-1151. https://doi.org/10.1097/ CCM.0000000000002335

9. Nielsen N, Wetterslev J, Al-Subaie N, Andersson B, Bro-Jeppesen J, Bishop G, Brunetti I, Cranshaw J, Cronberg T, Edqvist K, Erlinge D, Gasche Y, Glover G, Hassager C, Horn J, Hovdenes J, Johnsson J, Kjaergaard J, Kuiper M, Langorgen J, Macken L, Martinell L, Martner P, Pellis T, Pelosi P, Petersen P, Persson S, Rundgren M, Saxena M, Svensson R, Stammet P, Thoren A, Unden J, Walden A, Wallskog J, Wanscher M, Wise MP, Wyon N, Aneman A, Friberg H (2012) Target temperature management after out-of-hospital cardiac arrest - a randomized, parallel-group, assessor-blinded clinical trial—rationale and design. Am Heart J 163(4):541-548. https://doi. org/10.1016/j.ahj.2012.01.013

10. Nielsen N, Wetterslev J, Cronberg T, Erlinge D, Gasche Y, Hassager C, Horn J, Hovdenes J, Kjaergaard J, Kuiper M, Pellis T, Stammet P, Wanscher M, Wise MP, Aneman A, Al-Subaie N, Boesgaard S, Bro-Jeppesen J, Brunetti I, Bugge JF, Hingston CD, Juffermans NP, Koopmans M, Kober L, Langorgen J, Lilja G, Moller JE, Rundgren M, Rylander C, Smid O, Werer C, Winkel P, Friberg H, Investigators TTMT (2013) Targeted temperature management at $33^{\circ} \mathrm{C}$ versus $36^{\circ} \mathrm{C}$ after cardiac arrest. N Engl J Med 369(23):2197-2206. https://doi.org/10.1056/NEJMoa1310519

11. Dragancea I, Horn J, Kuiper M, Friberg H, Ullen S, Wetterslev J, Cranshaw J, Hassager C, Nielsen N, Cronberg T, Investigators TTMT (2015) Neurological prognostication after cardiac arrest and targeted temperature management $33^{\circ} \mathrm{C}$ versus $36^{\circ} \mathrm{C}$ : results from a randomised controlled clinical trial. Resuscitation 93:164-170. https://doi.org/10.1016/j.resuscitat ion.2015.04.013

12. Dragancea I, Wise MP, Al-Subaie N, Cranshaw J, Friberg H, Glover G, Pellis T, Rylance R, Walden A, Nielsen N, Cronberg T, Investigators TTMt (2017) Protocol-driven neurological prognostication and withdrawal of life-sustaining therapy after cardiac arrest and targeted temperature management. Resuscitation 117:50-57. https://doi.org/10.1016/j.resus citation.2017.05.014

13. Jennett B, Bond M (1975) Assessment of outcome after severe brain damage. Lancet 1(7905):480-484. https://doi.org/10.1016/s0140 $-6736(75) 92830-5$

14. Lybeck A, Friberg H, Aneman A, Hassager C, Horn J, Kjaergaard J, Kuiper M, Nielsen N, Ullen S, Wise MP, Westhall E, Cronberg T, Investigators TT-t (2017) Prognostic significance of clinical seizures after cardiac arrest and target temperature management. Resuscitation 114:146-151. https://doi. org/10.1016/j.resuscitation.2017.01.017

15. Hirsch LJ, LaRoche SM, Gaspard N, Gerard E, Svoronos A, Herman ST, Mani $\mathrm{R}$, Arif $\mathrm{H}$, Jette N, Minazad Y, Kerrigan JF, Vespa P, Hantus S, Claassen J, Young GB, So E, Kaplan PW, Nuwer MR, Fountain NB, Drislane FW (2013) American clinical neurophysiology society's standardized critical care EEG terminology: 2012 version. J Clin Neurophysiol 30(1):1-27. https://doi. org/10.1097/WNP.0b013e3182784729

16. Westhall E, Rosen I, Rossetti AO, van Rootselaar AF, Wesenberg Kjaer $T$, Friberg H, Horn J, Nielsen N, Ullen S, Cronberg T (2015) Interrater variability of EEG interpretation in comatose cardiac arrest patients. Clin Neurophysiol 126(12):2397-2404. https://doi.org/10.1016/j.clinph.2015.03.017

17. Wijdicks EF, Hijdra A, Young GB, Bassetti CL, Wiebe S, Quality Standards Subcommittee of the American Academy of Neurology (2006) Practice parameter: prediction of outcome in comatose survivors after cardiopulmonary resuscitation (an evidence-based review): report of the Quality Standards Subcommittee of the American Academy of Neurology. Neurology 67(2):203-210. https://doi.org/10.1212/01.wnl.0000227183.21314 .cd

18. Zandbergen EG, Hijdra A, Koelman JH, Hart AA, Vos PE, Verbeek MM, de Haan RJ, PROPAC Study Group (2006) Prediction of poor outcome within the first 3 days of postanoxic coma. Neurology 66(1):62-68. https://doi. org/10.1212/01.wnl.0000191308.22233.88

19. Bongiovanni F, Romagnosi F, Barbella G, Di Rocco A, Rossetti AO, Taccone FS, Sandroni C, Oddo M (2020) Standardized EEG analysis to reduce the uncertainty of outcome prognostication after cardiac arrest. Intensive Care Med. https://doi.org/10.1007/s00134-019-05921-6

20. Zhou SE, Maciel CB, Ormseth CH, Beekman R, Gilmore EJ, Greer DM (2019) Distinct predictive values of current neuroprognostic guidelines in post-cardiac arrest patients. Resuscitation. https://doi.org/10.1016/j.resus citation.2019.03.035

21. Moseby-Knappe M, Pellis T, Dragancea I, Friberg H, Nielsen N, Horn J, Kuiper M, Roncarati A, Siemund R, Unden J, Cronberg T, Investigators TT-t 
(2017) Head computed tomography for prognostication of poor outcome in comatose patients after cardiac arrest and targeted temperature management. Resuscitation 119:89-94. https://doi.org/10.1016/j.resus citation.2017.06.027

22. Team RC (2017) R: a language and environment for statistical computing. R Foundation for Statistical Computing, Vienna. https://www.R-proje ct.org/

23. Elmer J, Rittenberger JC, Faro J, Molyneaux BJ, Popescu A, Callaway CW, Baldwin M, Pittsburgh Post-Cardiac Arrest S (2016) Clinically distinct electroencephalographic phenotypes of early myoclonus after cardiac arrest. Ann Neurol 80(2):175-184. https://doi.org/10.1002/ana.24697

24. Backman S, Westhall E, Dragancea I, Friberg H, Rundgren M, Ullen S, Cronberg T (2017) Electroencephalographic characteristics of status epilepticus after cardiac arrest. Clin Neurophysiol 128(4):681-688. https:// doi.org/10.1016/j.clinph.2017.01.002

25. Amorim E, Ghassemi MM, Lee JW, Greer DM, Kaplan PW, Cole AJ, Cash SS, Bianchi MT, Westover MB (2018) Estimating the false positive rate of absent somatosensory evoked potentials in cardiac arrest prognostication. Crit Care Med 46(12):e1213-e1221. https://doi.org/10.1097/ CCM.0000000000003436

26. Rossetti AO, Oddo M, Logroscino G, Kaplan PW (2010) Prognostication after cardiac arrest and hypothermia: a prospective study. Ann Neurol 67(3):301-307. https://doi.org/10.1002/ana.21984

27. Callaway CW, Donnino MW, Fink EL, Geocadin RG, Golan E, Kern KB, Leary M, Meurer WJ, Peberdy MA, Thompson TM, Zimmerman JL (2015) Part 8: post-cardiac arrest care: 2015 American Heart Association guidelines update for cardiopulmonary resuscitation and emergency cardiovascular care. Circulation 132(18 Suppl 2):S465-S482. https://doi.org/10.1161/ CIR.0000000000000262

28. Sandroni C, Cavallaro F, Callaway CW, D'Arrigo S, Sanna T, Kuiper MA, Biancone M, Della Marca G, Farcomeni A, Nolan JP (2013) Predictors of poor neurological outcome in adult comatose survivors of cardiac arrest: a systematic review and meta-analysis. Part 2: patients treated with therapeutic hypothermia. Resuscitation 84(10):1324-1338. https://doi. org/10.1016/j.resuscitation.2013.06.020

29. Sandroni C, Cavallaro F, Callaway CW, Sanna T, D'Arrigo S, Kuiper M, Della Marca G, Nolan JP (2013) Predictors of poor neurological outcome in adult comatose survivors of cardiac arrest: a systematic review and meta-analysis. Part 1: patients not treated with therapeutic hypothermia. Resuscitation 84(10):1310-1323. https://doi.org/10.1016/j.resuscitat ion.2013.05.013

30. Scarpino M, Carrai R, Lolli F, Lanzo G, Spalletti M, Valzania F, Lombardi M, Audenino D, Contardi S, Celani MG, Marrelli A, Mecarelli O, Minardi C, Minicucci F, Politini L, Vitelli E, Peris A, Amantini A, Sandroni C, Grippo A, ProNe CAsg (2020) Neurophysiology for predicting good and poor neurological outcome at 12 and $72 \mathrm{~h}$ after cardiac arrest: the ProNeCA multicentre prospective study. Resuscitation 147:95-103. https://doi. org/10.1016/j.resuscitation.2019.11.014

31. Kim JH, Kim MJ, You JS, Lee HS, Park YS, Park I, Chung SP (2019) Multimodal approach for neurologic prognostication of out-of-hospital cardiac arrest patients undergoing targeted temperature management. Resuscitation 134:33-40. https://doi.org/10.1016/j.resuscitation.2018.11.007

32. Maciel CB, Youn TS, Barden MM, Dhakar MB, Zhou SE, Pontes-Neto OM, Silva GS, Theriot JJ, Greer DM (2020) Corneal reflex testing in the evaluation of a comatose patient: an Ode to precise semiology and examination skills. Neurocrit Care. https://doi.org/10.1007/s12028-019-00896-0

33. Streitberger KJ, Endisch C, Ploner CJ, Stevens R, Scheel M, Kenda M, Storm C, Leithner C (2019) Timing of brain computed tomography and accuracy of outcome prediction after cardiac arrest. Resuscitation 145:8-14. https ://doi.org/10.1016/j.resuscitation.2019.09.025

34. Wang G-N, Chen X-F, Lv J-R, Sun N-N, Xu X-Q, Zhang J-S (2018) The prognostic value of gray-white matter ratio on brain computed tomography in adult comatose cardiac arrest survivors. J Chin Med Assoc 81(7):599604. https://doi.org/10.1016/j.jcma.2018.03.003

35. Solari D, Rossetti AO, Carteron L, Miroz JP, Novy J, Eckert P, Oddo M (2017) Early prediction of coma recovery after cardiac arrest with blinded pupillometry. Ann Neurol 81(6):804-810. https://doi.org/10.1002/ana.24943

36. Oddo M, Sandroni C, Citerio G, Miroz JP, Horn J, Rundgren M, Cariou A, Payen JF, Storm C, Stammet P, Taccone FS (2018) Quantitative versus standard pupillary light reflex for early prognostication in comatose cardiac arrest patients: an international prospective multicenter double-blinded study. Intensive Care Med 44(12):2102-2111. https://doi. org/10.1007/s00134-018-5448-6

37. Moseby-Knappe M, Mattsson N, Nielsen N, Zetterberg H, Blennow K, Dankiewicz J, Dragancea I, Friberg H, Lilja G, Insel PS, Rylander C, Westhall E, Kjaergaard J, Wise MP, Hassager C, Kuiper MA, Stammet P, Wanscher MCJ, Wetterslev J, Erlinge D, Horn J, Pellis T, Cronberg T (2019) Serum neurofilament light chain for prognosis of outcome after cardiac arrest. JAMA Neurol 76(1):64-71. https://doi.org/10.1001/jamaneurol.2018.3223

38. Mattsson N, Zetterberg H, Nielsen N, Blennow K, Dankiewicz J, Friberg H, Lilja G, Insel PS, Rylander C, Stammet P, Aneman A, Hassager C, Kjaergaard J, Kuiper M, Pellis T, Wetterslev J, Wise M, Cronberg T (2017) Serum tau and neurological outcome in cardiac arrest. Ann Neurol 82(5):665-675. https ://doi.org/10.1002/ana.25067

39. Dankiewicz J, Cronberg T, Lilja G, Jakobsen JC, Belohlavek J, Callaway C, Cariou A, Eastwood G, Erlinge D, Hovdenes J, Joannidis M, Kirkegaard H, Kuiper M, Levin H, Morgan MPG, Nichol AD, Nordberg P, Oddo M, Pelosi P, Rylander C, Saxena M, Storm C, Taccone F, Ullen S, Wise MP, Young P, Friberg H, Nielsen N (2019) Targeted hypothermia versus targeted Normothermia after out-of-hospital cardiac arrest (TTM2): a randomized clinical trial-Rationale and design. Am Heart J 217:23-31. https://doi. org/10.1016/j.ahj.2019.06.012

40. Eastwood GM, Young PJ, Bellomo R (2014) The impact of oxygen and carbon dioxide management on outcome after cardiac arrest. Curr Opin Crit Care 20(3):266-272. https://doi.org/10.1097/MCC.00000000000000084

41. Nolan JP, Soar J, Cariou A, Cronberg T, Moulaert VR, Deakin CD, Bottiger BW, Friberg H, Sunde K, Sandroni C (2015) European resuscitation council and european society of intensive care medicine 2015 guidelines for post-resuscitation care. Intensive Care Med 41(12):2039-2056. https://doi. org/10.1007/s00134-015-4051-3 